\title{
Assessment of healthcare waste generation and its management systems: A prevalence survey of the healthcare facilities in Madagascar
}

\author{
Rajaonarison Hantanirina Odette ${ }^{1 *}$, Jacob Masika ${ }^{2}$, Tata Venance ${ }^{3}$, Joella Eldie \\ Soatiana $^{4}$, Ndjiembi Adjonga Christiane ${ }^{5}$, Camara Mohamed Lamine ${ }^{1}$, Lu Bin $^{1}$ \\ ${ }^{I}$ Key Laboratory of Environment and Health, Ministry of Education and Ministry of Environmental Protection, \\ School of Public Health, Tongji Medical College, Huazhong University of Science and Technology, \#13 \\ Hangkong Road, Wuhan, Hubei 430030, China \\ ${ }^{2}$ Department of Medical Physiology, Faculty of Health Sciences, Egerton University, Nakuru, Kenya \\ ${ }^{3}$ Environmental Health Services, Ministry of Public Health, Madagascar. \\ ${ }^{4}$ Department of Ophthalmology, Tongji Medical College of Huazhong University of Science and Technology, \\ Wuhan, China \\ ${ }^{5}$ School of Medicine and Health Management, Tongji Medical College of Huazhong University of Science and \\ Technology, Wuhan, China
}

\begin{abstract}
Healthcare waste is a major public health hazard in developing countries. The aim of this study was to assess healthcare waste management (HCWM) system currently employed in selected healthcare facilities (HCFs) in Madagascar.Data was collected through a questionnaire and field visit in 2009. Seventeen HCFs were randomly selected from seventy six HCFs whose staff had undergone HCWM in 2006. The quantity of infectious waste generated per day at the HCFs was in proportion to the number beds $(r=0.838$ and $p<0.05)$. Non-sharps infectious waste was positively correlated with sharps $(r=0.709, p=0.001)$. The availability of waste management plan was reported in $52.9 \%$ while the implementation of color coding system for waste segregation was reported in $76.5 \%$ HCFs. Waste segregation was reported by majority of HCFs ( $82 \%)$. Moreover, the most common disposal method was Montfort incinerator (65\%). In general, there was improved HCWM system in $H C F s$ surveyed, although certain HCFs still had poor management due to inadequate infrastructure and equipment for segregation, collection, transport, and disposal of medical waste (MW) as well as poor waste generation records. Interventions strategies should include adherence to national regulatory framework, periodic training and sensitization of healthcare worker and increased allocation of resources for HCWM.
\end{abstract}

Key words: Healthcare waste, generation rate, HCWM system, healthcare facilities

\section{Introduction}

As a basic definition, United States Environmental Protection Agency (USEPA) has defined medical wastes (MW) as containing all waste materials generated by HCFs, such as hospitals, clinics, physician's offices, dental practices, blood banks, and veterinary hospitals/clinics, as well as at medical research facilities and laboratories. This definition contains, but is not limited to, blood-soaked bandages, culture dishes and other glassware, discarded surgical gloves, discarded surgical instruments, discarded hypodermic needles (e.g., medical sharps), microbiological cultures, stocks, swabs used to inoculate cultures and withdrawn body organs after a surgery [1]. According to the World Health Organization (WHO), HCW is defined as the total waste streams [2] that include a wide range of materials, such as used needles and syringes, soiled dressings, body parts, diagnostic samples, blood, chemicals, pharmaceuticals, medical devices and radioactive materials [3]. In detail, it can be classified into eight main categories including general waste, chemical waste, pathological waste, radioactive waste, infectious waste, sharps, pharmaceutical waste and pressurized containers [4].

Improper MW management results in adverse effects on the environment and the public health [5]. Numerous studies have reported that the inappropriate handling and disposal of HCW poses health risks to health workers who may be directly exposed and to people near health facilities, particularly children and scavengers who may become exposed to infectious waste and a higher risk of diseases like hepatitis and HIV/AIDS [6-8]. For instance, 5.2 million people including 4 million children are reported to die annually from MW-related diseases [9]. WHO estimated that in 2000, around 23 million people were infected with Hepatitis B, Hepatitis C and HIV worldwide due to injections using contaminated syringes in HCFs [10]. In addition, environmental nuisance may also arise due to foul odor, flies, cockroaches, rodents, and vermin as well as contamination of underground water tables by untreated MW in landfills [11]. The use of poorly designed incinerators can cause the generation of hazardous pollutants $[12,13]$ including particulate matter, mercury, 
dioxin and furans [14] that pollute the environment and may lead to impairment of the immune system, and impaired development of the nervous system, the endocrine system and the reproductive functions [15].

In fact, Healthcare waste management (HCWM) entails all activities that lead to proper and safe disposal of waste produced from HCFs or a process that helps ensure proper hygiene in the health institution and safety of healthcare workers and communities $[16,17]$. These activities or process consists of generation, segregation, transportation, storage, treatment and safe disposal of all type of waste generated in HCFs [18] where national legislation must be followed. Waste generation designates the weight or volume of materials and products that enter the waste stream before recycling, composting, landfilling, or combustion takes place [19]. It can be dependent on type of HCFs, hospital specialization, available waste segregation options, seasonal variation, the number of hospital beds, and proportion of patients treated on a daily basis [20]. Four major categories of HCW have been recommended for organizing the process of HCWM such as sharps, whether infectious or not; non-sharps infectious waste; general waste; and other hazardous waste. Collection, storage and treatment of these wastes are differed from each other.Segregation of waste separates the HCW by type and puts all them in a safety box and other containers with different colors [21]. For example, keep infectious and potentially infectious waste in yellow or red containers with a biohazard logo; place non-infectious general waste in black containers or bags. Brown bags are often used for pharmaceutical and chemical waste.

Incineration, disinfection, sterilization, plasma arc and land filling have been adopted for the treatment of HCW in different parts of the world but in most of the developing Asian countries, infectious, pathological wastes and sharps are incinerated rarely with required air pollution control/open burned and the ash is disposed along with the municipal waste [18].

In light of public health and environmental safety, WHO emphasizes controlling and managing medical waste by choosing suitable methods that reflect local condition of each country [22]. However, HCWM continues to present an array challenge for many developing countries [23], where it is hampered by technological, economic, social difficulties and inadequate training of staff responsible for the handling and processing of wastes [24].Several studies in Africa point out that medical waste management is still in its infancy; characterized by the lack of awareness on the impacts of HCW, the total absence of medical waste regulations and a high incidence of non-compliance in cases where they are existing [25-27]. MW are still handled and disposed together with domestic wastes, thus creating a great health risk to municipal workers, the public, and the environment [28]. Also, waste disposal options are limited, and small-scale incinerators have been used as an interim solution [29].

In Madagascar, most of the MW are generally buried [30]. Only about 519,758 $\mathrm{kg}$ of wastes are generally burnt annually against large quantities of $1,011,537 \mathrm{~kg}$ wastes that are reported as disposed by simple burial [30]. In 2004, it was reported that more than $60 \%$ of 80 health facilities assessed, disposed their wastes by open burning and burial. Used syringes and needles are reported to be seen in some courtyards of these HCFs [31]. Majority of artisanal incinerators are poorly designed and not efficient in terms of total combustion of MW [32]. Additionally, many people are unaware the effects of MW as a source of infections that can lead to death [33].Like many developing countries, Madagascar strives to enhance its HCWM and achieve good management. The ministry of public health (MOPH) of Madagascar validated a document of national policy (NP) on healthcare waste management and injection safer (HCWMIS) defining the objectives, the strategies and the national action plan which extended from 2005 to 2008 for tackling the challenges [31]. To ensure the improvement of medical waste management and reinforce its strategic interventions in Madagascar, it is important to understand and evaluate the currentmedical waste management system before making recommendations on proper remediation measures. Therefore, the purpose of this study was to assess the amount of HCW, the suitability and adequacy of equipment and infrastructure for safe or proper disposal of MW in HCFs of Madagascar. The review on the status of HCWM may provide workable recommendations that could foster changes in the way HCW is managed.

\subsection{Study area}

\section{Materials and methods}

The health system in Madagascar is structured at four levels: Basic Health Center level 1 and level 2 (BHC1 and BHC2),District Hospital level 1 and level 2 (DH1 and DH 2), Regional Referral Hospitals (RRH),and University Hospital (UH) [34]. The total number of the HCFs in each categories were 2494, 86, 18 and 4 respectively [35].The study was carried out in 17 hospitals such as $1 \mathrm{UH}, 07 \mathrm{RRH}, 05 \mathrm{DH} 1$ and $04 \mathrm{DH} 2$ and its number of the beds was included between 15 and 425 beds. These HCFs were selected from the random draw of the 76 HCFs in which their leaders were trained in HCWM in 2006. Then, this study focused on investigating because it was assumed that the categories of HCFs would generate more $\mathrm{HCW}$ in the city than others mainly due to their relatively large numbers of staff and patient. Thus, it was conducted on 17 HCFs (about $80 \%$ response rate). In addition, the study on these HCFs was also considered sufficient to understand the current waste management system in Madagascar. 


\subsection{Data source}

The data used in this study come from a survey conducted in 2009. The aim of this investigation was to evaluate the effectiveness of NP on HCWM regarding five elements: the structure and equipment of HCFs, the legislative and regulatory framework, promotional activities, financing mechanism and the establishment of monitoring system.In our study, we were interested inthe structure and equipment of HCWM in the HCFs. These data were obtained by administering questionnaires to hospital staff such as consultants, medical officers, paramedics (matrons, nurses, cleaners, pharmacists), and administrative personnel. The questionnaires were designed in such a way as to enable respondents indicate the HCW generated in the $\mathrm{HCFs}$ and its management system. It was structured to generate the following data:

1. Number of beds and quantity of waste produced in the HCFs

2. Availability of waste management plan

3. Use of proper color coding system with recommended containers for sorting, collecting and transporting waste

4. Waste segregation practice

5. Waste disposal methods provided.

6. Adequacy of the protective wear and cleaning equipment

7. Availability of information education and communication (IEC) materials or tools

\subsection{Data analysis}

Data about the quantity of HCW was analyzed using SPSS version 16. Although it was abnormally distributed, medians and ranges were determined to calculate the MW generation in these HCFs. Then, significance testing the bivariate associations between the total amount of waste and the number of beds was conducted using Spearman's rank correlation coefficient (r) [36]. P-value and $r$ have been reported to present the extent strength between two variables [37]. P-value $<0.05$ was considered significant. Different descriptive statistics were used to evaluate the waste management system.

\subsection{Generation rate of $\mathrm{HCW}$}

\section{Results}

The median generation rate of non-sharps infectious waste and sharps in these HCFs was about 23.57 $\mathrm{kg}$ /day (range: $13.57-92.86 \mathrm{~kg} /$ day) and $3.43 \mathrm{~kg}$ /day (range: $1.00-28.57 \mathrm{~kg}$ /day) respectively (Table 1 ). The highest generation rate of total HCW studied was found at UH (121.43 kg/day) and the lowest at DH1 (15.29 $\mathrm{kg}$ /day). With regard to the number of the beds, the median generation rate of non-sharps infectious waste and sharps totaled about $0.57 \mathrm{~kg} / \mathrm{bed} /$ day (range: $0.22-1.34 \mathrm{~kg} / \mathrm{bed} /$ day) and $0.08 \mathrm{~kg} / \mathrm{bed} /$ day (range: $0.03-0.18$ $\mathrm{kg} / \mathrm{bed} /$ day) respectively. The highest generation rate of this total $\mathrm{HCW}$ was found at DH1 $(1.48 \mathrm{~kg} / \mathrm{bed} / \mathrm{day})$ and the lowest at UH $(0.29 \mathrm{~kg} / \mathrm{bed} /$ day $)$. The median was valued $0.65 \mathrm{~kg} / \mathrm{bed} / \mathrm{day}$. It was observed that the variation of the MW amount depended on the factors such as number of the beds, categories of hospitals, management of HCW and so on. There was a positive correlation between the total MW generated (kg/day) and the number of beds $(\mathrm{r}=0.838$ and $\mathrm{p}<0.05)$ (Figure 1$)$, between the quantity of non-sharps infectious waste $(\mathrm{kg} / \mathrm{bed})$ and the number of the beds $(\mathrm{r}=0.813 ; \mathrm{p}<0.05)$ (Figures 2$)$ and between the sharps $(\mathrm{kg} / \mathrm{day})$ and the number of the beds $(r=0.656 ; \mathrm{p}=0.004)$ (Figure 3$)$. Similarly, the quantity of sharps (kg/day) was positively correlated with the quantity of non-sharps infectious waste in these HCFs $(r=0.709$ and $p=0.001)$ (Figure 4).

Table 1 Daily quantity of infectious wastes generated in the HCFs

\begin{tabular}{|c|c|c|c|c|c|c|c|}
\hline \multicolumn{3}{|c|}{ kg bed day } & \multicolumn{3}{|c|}{$\operatorname{kg} d y$} & N & Type of Infectious watte \\
\hline Median & Maximum & Minimum & Median & Maximum & Minimum & & \\
\hline 0.57 & 1.34 & 0.22 & 218.57 & 92,86 & 13.57 & 17 & Non-sharps \\
\hline 0.08 & 0.18 & 0.03 & 34 & 28.87 & 1.00 & 17 & Sharpi \\
\hline 0.65 & 1.48 & 0.19 & 30.99 & 121,43 & 15.29 & 17 & Total \\
\hline
\end{tabular}




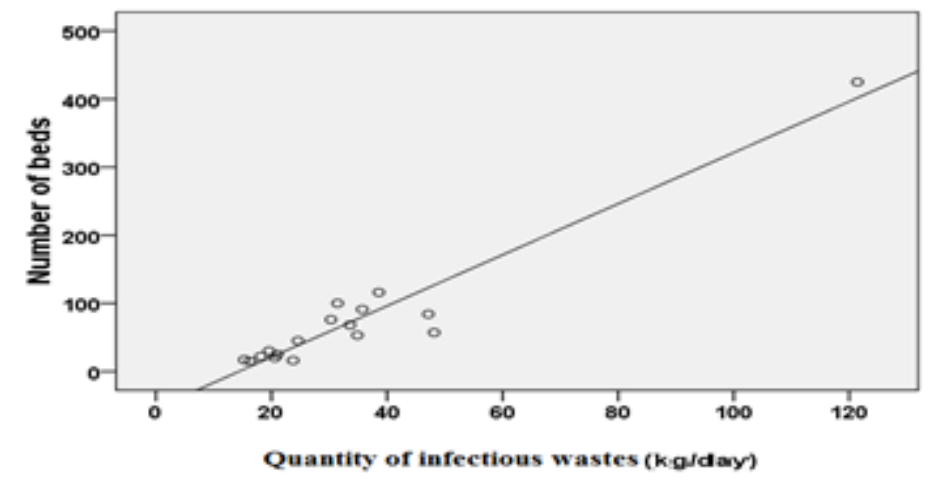

Figure1. Scatter plot showing the number of beds correlated with the quantity of infectious waste $(\mathrm{r}=\mathbf{0 . 8 3 8}$ and $\mathrm{p}<0.05)$

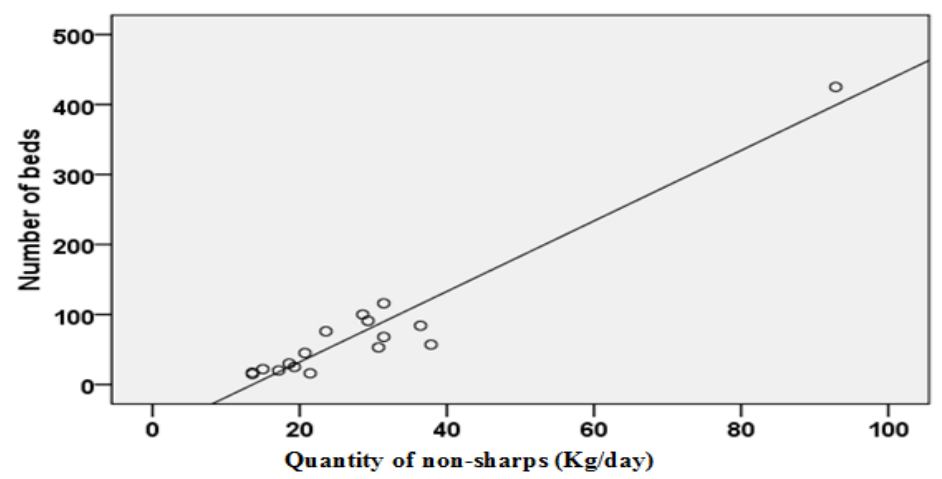

Figure2. Scatter plot showing the quantity of non-sharps waste correlated with the number of beds $(r=0.813$ and $p<0.05)$

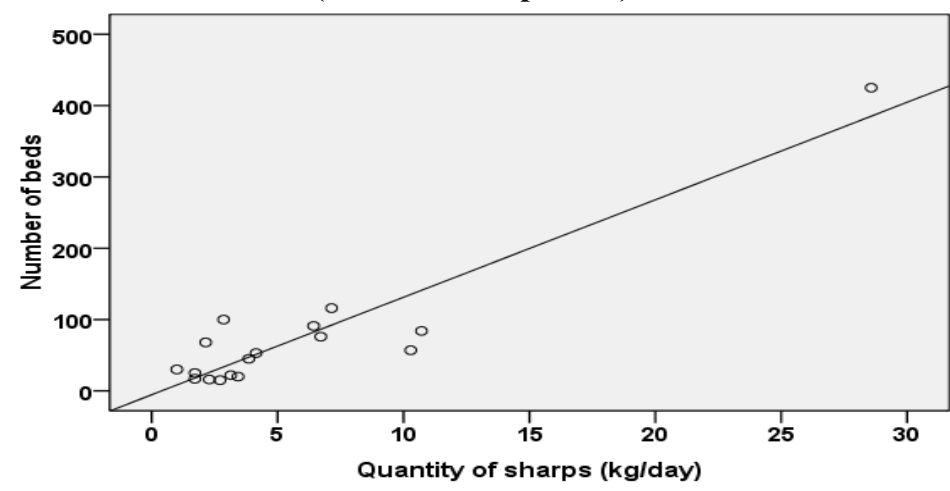

Figure3. Scatter plot showing the quantity of sharps correlated with the number of beds

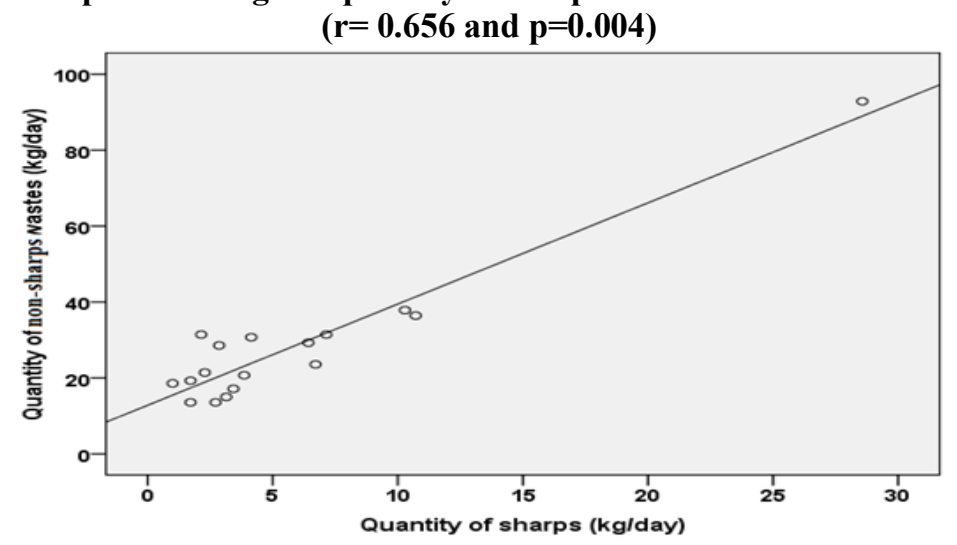

Figure4.Scatter plot showing the quantity of sharps correlated with the quantity of non-sharps infectious waste $(r=0.709$ and $p=0.001)$ 


\subsection{Waste management systems}

Availability of waste management plan (WMP)

The eventual existence of validated WMP in the selected HCFs was found that several HCFs including $\mathrm{DH} 1, \mathrm{DH} 2$, RRH still hadn't WMP $(60 \%, 50 \%$ and $43 \%$ respectively) but in general, nine out seventeen (52.94\%) implemented the plan (Table 2).

Table 2 Availability of validated WMP in the surveyed HCFs in Madagascar.

\begin{tabular}{|c|c|l|}
\hline & Availa bility of validated WMP & Categories of healthcare facilities \\
\hline$\%$ & $\mathrm{~N}^{\circ}$ & \\
\hline 40 & 2 & $\mathrm{DHl}(\mathbf{5})^{*}$ \\
\hline 50 & 2 & $\mathrm{DH} 2(4)$ \\
\hline 57 & 4 & $\mathrm{RRH}(7)$ \\
\hline 100 & 1 & $\mathrm{UH}(1)$ \\
\hline $\mathbf{5 2 . 9 4}$ & 9 & Total $(17)$ \\
\hline
\end{tabular}

*Numbers in parentheses represent the total of HCFs studied in different categories

\section{Waste segregation, collection and transportation}

Most of the HCFs used color coding bins $(60 \%$ of DH1, $75 \%$ of DH $2,86 \%$ of RRH and $100 \%$ of UH) and all of HCFs assessed had recommended containers for sorting, collecting and transporting waste (Figure 5 and 6). Those that didn't have were observed especially in the small HCFs as DH1. Most of HCFs practiced the waste segregation except $40 \%$ of DH1 and $14.3 \%$ of RRH where the general waste was still mixed with infectious waste in the dustbins from the production until the disposal of waste (Table 3 ).

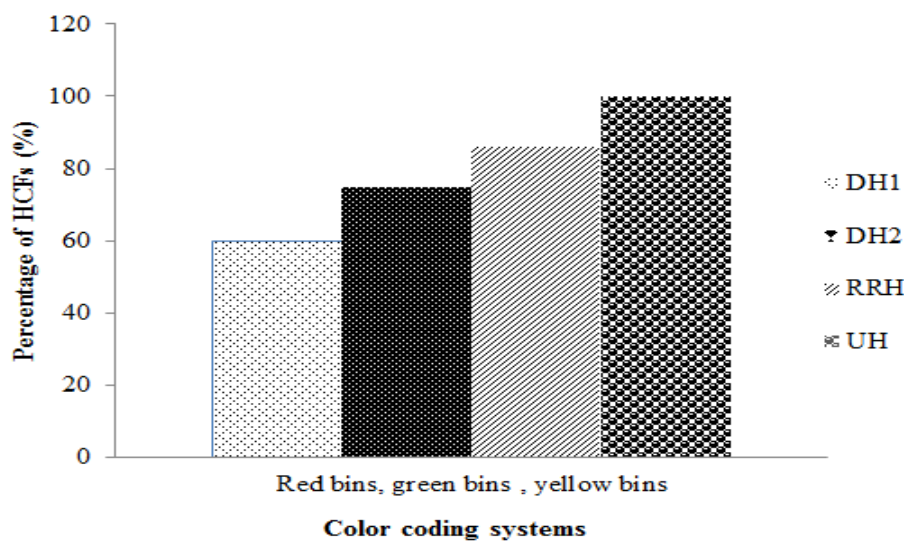

Figure 5. Color coding systems implemented in the surveyed HCFs

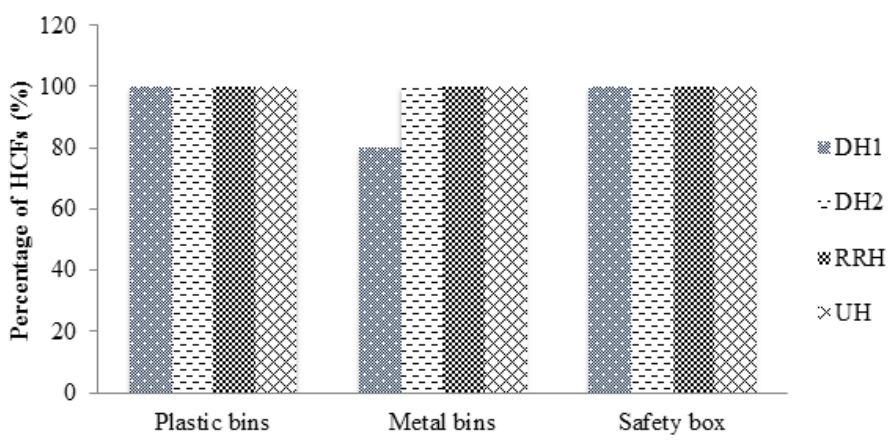

Type of recommended containers

Figure 6. Recommended containers used by the selected HCFs 
Assessment of healthcare waste generation and its management systems: A prevalence.....

Table 3 Waste segregation practice in the designated HCFs

\begin{tabular}{|c|c|l|}
\hline & Practice of waste segregation & Categories of healthcare facilities \\
\hline$\%$ & $\mathrm{~N}^{\mathbf{2}}$ & \\
\hline 60 & 3 & $\mathrm{DHl}(\mathbf{5}) *$ \\
\hline 100 & 4 & $\mathrm{DH} 2(4)$ \\
\hline 85.7 & 6 & $\mathrm{RRH}(7)$ \\
\hline 100 & 1 & $\mathrm{UH}(1)$ \\
\hline 82.35 & 9 & Total $(17)$ \\
\hline
\end{tabular}

\section{Waste disposal methods and other equipmentneeded}

Open air burning, single chamber incinerator and Montfort incinerators were most common type of disposal methods in the surveyed HCFs (Figure 7). Many HCFs (65\%) disposed their waste in the Montfort incinerators because it was considered to conform according to the national policy. $35 \%$ of HCFs reported using non-conformity waste disposal.The most common type of cleaning equipment found in these HCFs was shovels, scrapers and brooms (Figure 8). The main protective equipment used by most HCFs was gloves, masks, boots and coveralls (Figure 9). Only DH1(60\%) and RRH(14.3\%) didn `t display IEC materials needed for sensitizing visitors, patients, healthcare workers and others to pay attention to $\mathrm{HCW}$ in order to prevent health and environmental risks (Table 4).

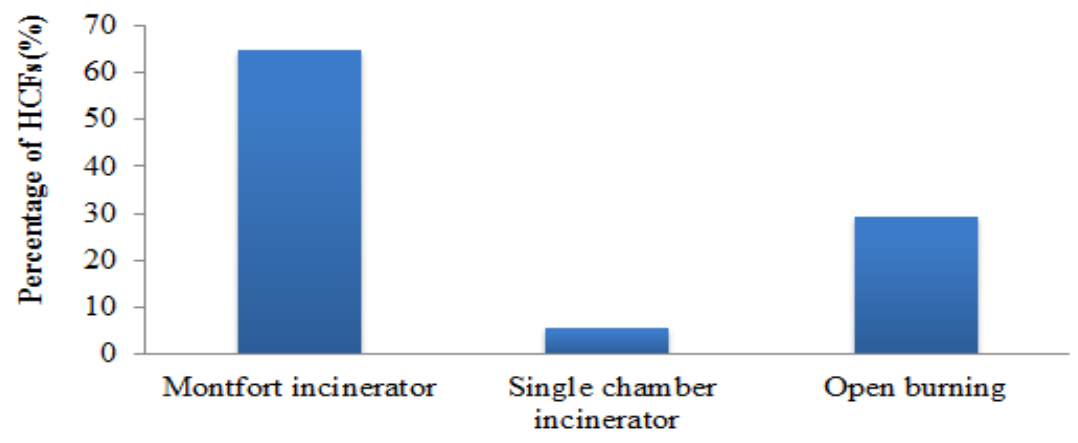

Type of disposal methods

Figure 7. Type of disposal methods in the seventeen HCFs studied

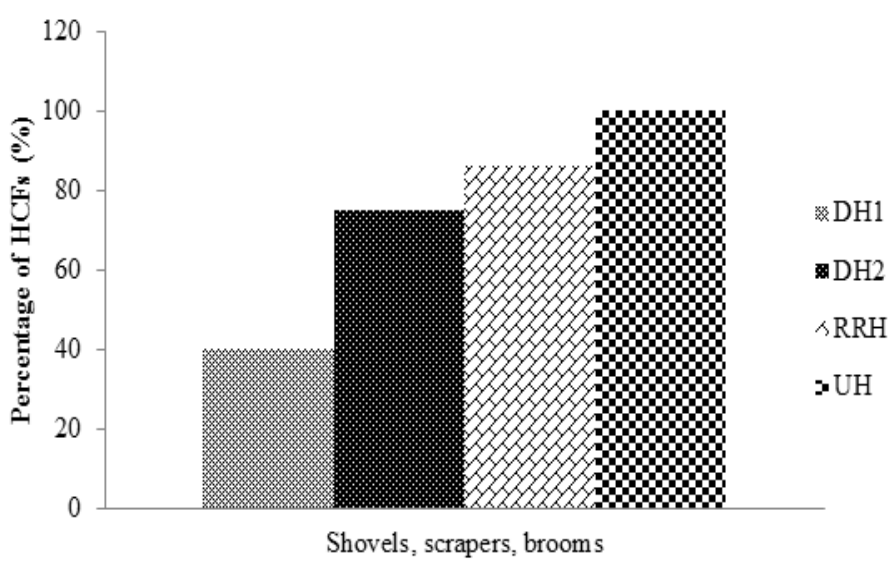

Type of cleaning equipment

Figure 8. Type of cleaning equipment in the surveyed HCFs 


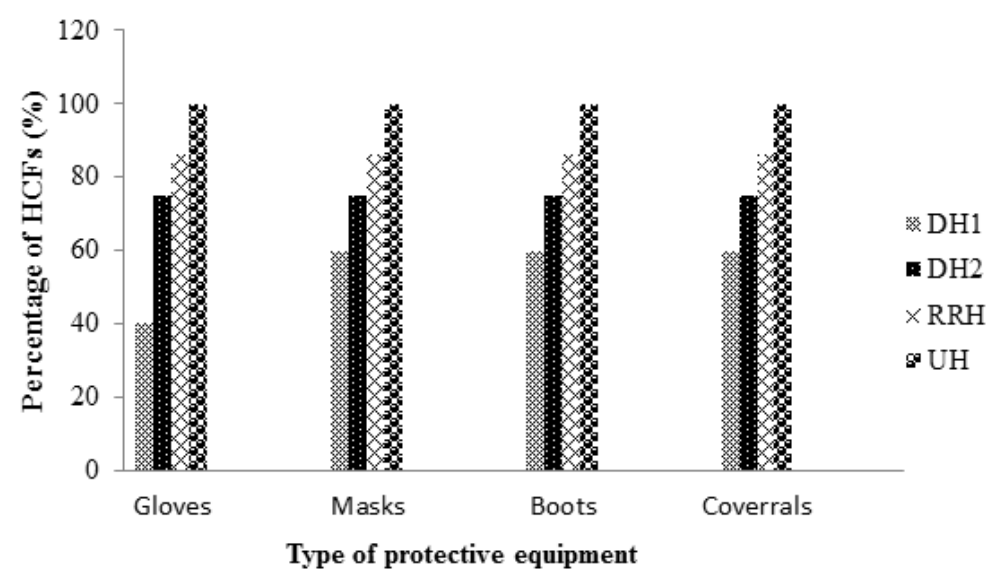

Figure 9. Type of protective equipment in the assessed HCFs

Table 4 Availability of IEC tools for sensitization in the studied HCFs

\begin{tabular}{|c|c|l|}
\hline & Availability of IEC tools & Categories of healthcare facilities \\
\hline$\%$ & $\mathbf{N}^{\text {0 }}$ & \\
\hline 40 & 2 & $\mathrm{DHl}(5)^{*}$ \\
\hline 100 & 4 & $\mathrm{DH} 2(4)$ \\
\hline 85.7 & 5 & $\mathrm{RRH}(7)$ \\
\hline 100 & 1 & $\mathrm{TH}(1)$ \\
\hline 70.6 & 12 & $\mathrm{Total}(17)$ \\
\hline
\end{tabular}

\subsection{Generation rate of $\mathrm{HCW}$}

\section{Discussion}

The highest generation rate for infectious wastes in the surveyed HCFs in Madagascar was found at DH1 (1.48 kg/bed/day) and the lowest was at UH $(0.29 \mathrm{~kg} / \mathrm{bed} /$ day $)$. This difference may be due to number beds and the waste management process because UH had a larger number of the bed than DH1 and those that reported provided a poor HCWM were found especially in DH1.HCFs generate different kind of wastes in which non-sharps infectious waste and sharps are among the hazardous wastes that can cause serious health problems particularly for waste collectors, hospital patients and healthcare workers. The infectious wastegenerated from the surveyed HCFs $(0.65 \mathrm{~kg} / \mathrm{bed} /$ day $)$ was higher than that estimated by the NGO Voarisoa in 1999 at the hospitals in Madagascar (about $0.065 \mathrm{~kg} / \mathrm{bed} /$ day) [32]. The increase in waste production was not only due to the increase in population, but also the improvement of waste management process because before 2005, there was no national policy, internal regulations, sensitization as well as training on HCWM in Madagascar. Thus, most of the HCW was put together with the general waste which decreased the quantity of $\mathrm{HCW}$ and increased the risk and spread of the diseases related to it as it was no longer handled as HCW.

The proportion of MW generated differs between countries. For example, about infectious waste, the mean waste generation in a university teaching hospital reached about $2.43 \mathrm{~kg} / \mathrm{bed} /$ day in Iran. In 10 hospitals in Tabriz (Iran), the average total production for infectious waste was $1.039 \mathrm{~kg} / \mathrm{bed} / \mathrm{day}$. Quantities of waste generated depended on the status of the hospital, level of instrumentation and sometimes location of the medical facility [38]. There were positive correlation between this total MW (kg/day), quantity of non-sharps infectious waste $(\mathrm{kg} / \mathrm{bed})$ or quantity of sharps $(\mathrm{kg} / \mathrm{day})$ and the number of beds $(\mathrm{r}=0.838, \mathrm{p}<0.05 ; \mathrm{r}=0.813, \mathrm{p}<0.05$ and $\mathrm{r}=$ $0.656, p=0.004$ respectively) in this study. Similar results were reported for nine general hospitals and twelve government hospitals in Central Macadonia where the amount of infectious waste ( $\mathrm{kg} / \mathrm{day}$ ) was linearly correlated with the number of beds [39]. Additionally, our study found a significant positive correlation $(\mathrm{r}=$ $0.709, \mathrm{p}=0.001)$ between the quantity of non-sharps infectious waste $(\mathrm{kg} /$ day) and sharps $(\mathrm{kg} / \mathrm{day})$. This correlation may be due to the separation of sharps from other infectious waste according to the classification of $\mathrm{HCW}$. It means increase in non-sharps infectious waste leads to increase use of sharps which may increase injury and health hazards, thus needed to be handled and well-disposed in a controlled manner to safeguard public health against injuries. 


\subsection{Waste management systems}

\section{Availability of waste management plan (WMP)}

In the present study, about half of surveyed HCFs didn't have waste management plan or procedure of internal HCW.In addition, there was the lack of reliable data on the waste generation because the quantities of waste had been estimated by observations and interview of the people responsible for incineration. A similar survey conducted in the $85 \mathrm{HCFs}$ in Zambia revealed that there was no waste management plan prepared in most of the HCFs (47 out of 85 HCFs) [40]. Most of the HCFs did not maintain records of waste generated contrary to ministry policy, legislation or regulations. This may lead to improper planning and allocation of resources.

\section{Waste segregation, collection and transportation}

It was found in this study that the majority of HCFs (76\%) implemented color coding system for waste segregation and recommended containers for sorting, collecting and transporting waste were practiced at all surveyed HCFs. This was significantly better compared with a study in Ethiopia which reported that none of the hospitals surveyed used a complete color coding system [37]. Comparable survey in Zambia showed that the majority of HCFs had no color coding in place which may lead to difficulties in segregation of waste [40]. According to the Alagoz and Kocasoy, in Istanbul, most of the healthcare institutions did not have appropriate color coded bags or containers for sorting the different types of waste [41]. Concerning the waste segregation practice, it was revealed that about $82 \%$ of the surveyed HCFs followed this practice. This result was comparable to studies done in South Africa and India which reported that about $97 \%$ and $67 \%$ respectively of HCFs segregated HCW into readily available waste bins [42, 43].A similar survey conducted in China showed that $73 \%$ of the hospitals used segregation in collection of HCW for all medical waste, while $27 \%$ of the hospitals did not implement segregation in collection of medical waste [44].

The present study also reported cases of noncompliance in segregation practice and color-coding system found especially in the small HCFs such as DH1. This may result in hazardous waste not only being disposed inappropriately, but also with members of the community gaining access to such waste.Likewise, in China, Gai et al. (2010) reported that primary health-care centers demonstrated a number of waste management inadequacies which were bigger than those of secondary or tertiary establishments [45]. Similar noncompliance had been reported in PHC assessments conducted in several developing countries such as Laos, Turkey, Mongolia, among others [46, 10 and 41].

\section{Waste disposal methods and other equipmentneeded.}

The disposal methods for HCW in the surveyed hospitalsconsisted of single chamber incinerator $(6 \%)$, open air burning $(29 \%)$ and use of Montfort incinerator $(65 \%)$. This was better than that reported by Muluken Azage where only four out of ten health centers (40\%) used local type of incinerators, while the rest $(60 \%)$ used open burning for the final disposal of HCW [47]. Similarly, a study in Hawassa city revealed that about $89 \%$ of the HCFs used low combustion incinerators and $11 \%$ of the HCFs used open burning of the waste as a treatment method [48]. Also, assessment conducted by WHO in 22 developing countries showed that the proportion of HCFs that do not use proper waste disposal methods ranges from 18\% to 64\% in 2002 [49]. Cleaning and protective equipment were applied in most of the surveyed HCFs $(70.6 \%$ and $76 \%$ respectively with gloves used commonly in about $70.6 \%$ of HCFs). These results were comparable to other places such Istanbul, where approximately $77 \%$ of the hospitals used appropriate equipment for collection and personnel [50]. Displayed IEC materials as instructive posters was found generally in most of HCFs (70.6\%) but those didn `t implemented found particularly in DH1 $(60 \%)$. The use of instructive posters was important for sensitization visitors, patients, healthcare workers and others to pay attention to the risks involved in reusing syringes and hypodermic needles or the infection-control benefits of waste segregation and treatment. A similar study achieved in Saudi Arabian hospital was reported the importance of providing instructive posters as tool to promote effective segregation of HCW [51].

\section{Conclusion}

It can be concluded that the performance in terms of implementation and adoption of NP on HCWMIS in Madagascar HCFs is moderately satisfactory. Comparable judgment was reported by the staff of the World Bank in 2008. However, majority of lower level HCFs still had some cases of poor HCWM and therefore we give the following recommendations:

- $\quad$ to emphasize adherence to set guidelines on safe management practices and safety procedure on HCWM and provision of equipment and infrastructure needed for HCWM

- guidelines Lobby for increased allocation of resources for better HCWM and implementation of set policies

- $\quad$ educational, informative and instructive posters, pamphlets and audio-visual aid to sensitizing health-care personnel as well as the public on safe HCWM practices 
- periodic audit of HCWM practices at all HCFs and recommendations for improvement

- continuous periodic training of healthcare workers and cleaning staff because staff training becomes imperative to create awareness on wastes, their effects, importance of existing guidelines and the implementation of the waste management options for the different categories of wastes so that hospitals do not become infection centers that contribute to health risk to the environment and humans [52].

Future research should include introduction of other factors such as patient flow in HCFs and inclusion of private HCFs to obtain specific information on HCW generation rate and its management system which is representative of the situation in the whole country. Finally, HCWM needs the involvement of all stakeholders.

[1]. United States Environmental Protection Agency, (2011)

[2]. URL: http://www.epa.gov/wastes/nonhaz/industrial/medical/ (accessed December 2011)

[3]. World Health Organization (WHO) Management of Solid Health Care Waste at Primary Health Centers, A Decision-Making Guide, WHO, Geneva 2005

[4]. Komilis D, Fouki A, Papadopoulos D. Hazardous medical waste generation rates of different categories of health-care facilities. Waste Management, 2012 Jul; 32(7):1434-41. doi: 10.1016/j.wasman.2012.02.015. Epub 2012 Mar 22. PMID: 22444895 [PubMed - indexed for MEDLINE]

[5]. Ahmed R. (1997). Hospital waste management in Pakistan. Case study report, UWEP, Gouda, The Netherlands. URL: http://www.bvsde.paho.org/bvsacd/cd48/pakistan.pdf

[6]. Ruoyan G, Lingzhong X, Huijuan L, Chengchao Z, Jiangjiang H, Yoshihisa S, et al. Investigation of health care wastemanagementin Binzhou District, China. Waste Management 2010; 30:246-50.

[7]. Adegbita MA, Nwafor SO, Afon A, Abegunde AA, Bamise CT. Assessment of dental waste management in a Nigerian tertiary hospital. Waste Manag Res. 2010; 28:769-777.

[8]. WHO. Wastes from Healthcare Activities. Fact Sheet No 231, April 2002. Available at:

[9]. http://www.who.int/mediacentre/ factsheets/fs231/en/; 2002. Accessed 12.09.09.

[10]. World Health Organization. Unsafe injection practices and transmission of blood borne pathogens. Bull World Health Organ. 1999; 77:787-819.

[11]. Akter, N., 2000. Medical Waste Management: A Review. Asian Institute of Technology, School of Environment, Resources and Development, Thailand.

[12]. Shinee E, Gombojav E, Nishimura A, Hamajima N, Ito K. Healthcare waste management in the capital city of Mongolia. Waste Management 2008; 28(2):435-41.

[13]. Nemathaga, F., Maringa, S., Chimuka, L., 2008. Hospital solid waste management practices in Limpopo Province, South Africa: a case study of two hospitals. Waste Management 28, 1236-1245.

[14]. Alagöz BAZ, Kocasoy G: Treatment and disposal alternatives for healthcare waste in developing countries - a case study in Istanbul, Turkey. Waste Manag Res 2007, 25(1):83-89.

[15]. Mahdi F, Arash M, Mohammadi MS, Jorfi S: Hospital waste management status in Iran: a case study in the teaching hospitals of Iran university of medical sciences. Waste Manag Res 2009, 27(4):384-389.

[16]. Malkan S, Nelson J. Global trends in responsible healthcare waste management e a perspective from health care without harm. Editorial J Waste Manage. 2005; 25: 570-572.

[17]. WHO, 2004. Safe health care-waste management. Policy paper. Downloaded from $<$ www.healthcarewaste.org $>$.

[18]. Sanitation Connection (2002), Healthcare Waste Management, http://www.sanicon.net/titles/topicintro.php3?topic1d=43. Accessed, 12 June, 2006.

[19]. Health Care Waste Management", At a Glance Series, World Bank, June 2003.

[20]. World Health Organization, 2008. Healthcare Waste and its Safe Management (accessed online at http://www.healthcarewaste.org).

[21]. http://www.wpro.who.int/philippines/publications/health_care_waste_management_manual_3rd_ed.pdf

[22]. Akter, N., 2000. Medical Waste Management: A Review. Asian Institute of Technology, School of Environment, Resources and Development, Thailand.

[23]. Khajuria A, Kumar A: Assessment of healthcare waste generated by Government Hospital in Agra city, India. Dep Environ Stud Sch Life Sci Ambedkar Univ 2007, 5:25-30.

[24]. World Health Organization (WHO), 2005. Management of Solid Health - Care Waste at Primary Health - Care Centers, a Decision-Making Guide. Geneva.

[25]. Alagöz AZ, Kocasoy G. Determination of the best appropriate management methods for the health-care wastes in Istanbul. Waste Management 2008; 28:1227-35.

[26]. Manga, V.E.; Forton, O.T.; Mofor, L.A.; Woodard, R .Health care waste management in Cameroon: A case study from the Southwestern Region. Resources, Conservation \& Recycling vol. 57 December, 2011. p. 108-116.

[27]. Bendjoudi Z, Taleb F, Abdelmalek F, Addou A. Healthcare waste management in Algeria and Mostaganem department. Waste Management 2009; 29:1383-7.

[28]. Longe OE, Williams A. A preliminary study of medical waste management in Lagos, Nigeria. Iranian Journal of Environmental Health Sciences and Engineering 2006; 3:133-9.

[29]. Soliman SM, Ahmed AI. Overview of biomedical waste management in selected Governorates in Egypt: a pilot study. Waste Management 2007; 27:1920-3.

[30]. Silva, C.E., Hoppe, A.E., Ravanello, M.M., Mello, N., 2005. Medical waste management in the south of Brazil. Waste Management $25(6), 600-605$.

[31]. Abd El-Salam MM. Hospital Waste Management in El-Beheira Governorate, Egypt. Journal of Environmental Management. 2010; 91 (3): 618-629. http://dx.doi.org/10.1016/j.jenvman.2009.08.012 [Pubmed] .

[32]. www.unep.org/.../MADAGASCAR\%20Hg\%20Inventory_Final_\&_Action_

[33]. http://documents.worldbank.org/curated/en/2005/09/7561543/madagascar-health-swap-environmental-assessment-politiquenationale-de-gestion-des-dechets-des etablissements-de-soins-de-securite-des-injections. 
[34]. http://documents.worldbank.org/curated/en/2005/02/5674053/madagascar-second multisectoral-hivaids-project-plan-de-gestiondes-dechets-issus-des-soins-de-sante United States Environmental Protection Agency, 2011.Available from: <http:// www.epa.gov/wastes/nonhaz/industrial/medical/> (accessed December 2011).

[35]. http://fr.allafrica.com/stories/201108012409.html

[36]. http://fmcmada.info/AVRIL2012/codesante.pdf

[37]. www.sante.gov.mg/Kers/Politik\%20prevention\%20et\%20lutte.

[38]. Gerald Van B, Lloyd D, Patrick J, Thomas L: Biostatistics: A Methodology for the Health Sciences. 2nd edition. USA: A John Wiley \& sons, INC; 2004.

[39]. Debere et al.: Assessment of the health care waste generation rates and its management system in hospitals of Addis Ababa, Ethiopia, 2011. BMC Public Health 2013 13:28.

[40]. Mato R. and Kaseva M. 1999. Critical review of industrial and medical waste practices in Dar-es-Salaam City. Resources, Conservation and Recycling, 25: 271-287.

[41]. Sanida G, Karagiannidis A, Mavidou F, Vartzopoulos D, Moussiopoulos N, Chatzopoulos S: Assessing generated quantities of infectious medical wastes: a case study for a health region administration in Central Macedonia, Greece. Waste Manag 2010, 30:532-538.

[42]. http://afrosai-e.org.za/sites/afrosai-e.org.za/files/reports/Medical\%20Waste\%20Management\%20(2010).pdf

[43]. Alagoz, A.Z., Kocasoy, G., 2008. Determination of the best appropriate management methods for the healthcare waste in Istanbul. Waste Management 28, 1227- 1235.

[44]. Ramokate T, Basu D: Healthcare waste management at an academic hospital: knowledge and practices of doctors and nurse. South African Medical Journal 2009; 99(6): 444-450.

[45]. Shafee M, Kasturwar NB, Nirupama N: Study of knowledge, attitude and practices regarding biomedical waste among paramedical workers. Indian Journal of Community medicine 2010; 35:369-370.

[46]. Yong Z1, Gang X, Guanxing W, Tao Z, Dawei J.Medical waste management in China: a case study of Nanjing.Waste Manag. 2009 Apr; 29(4):1376-82. doi: 10.1016/j.wasman.2008.10.023. Epub 2009 Jan 20.

[47]. Gai, R.Y., Xu, L.Z., Li, H.J., Zhou, C.C., He, J.J., Yoshihisa, S., et al., 2010. Investigation of health care waste management in Binzhou District, China. Waste Management 30 (2), 246-250.

[48]. Phengxay, S., Okumura, J., Miyoshi, M., Sakisaka, K., Kuroiwa, C., Phengxay, M., 2005. Health-care waste management in Lao PDR: a case study. Waste Management \& Research 23 (6), 571-581.

[49]. Muluken Azage, Abera Kumie. Healthcare waste generation and its management system: the case of health centers in West Gojjam Zone, Amhara Region, Ethiopia. Ethiop. J. Health Dev. 2010; 24(2):119-126.http://ejhd.uib.no/ejhd-v24n2/119\%20Healthcare\%20waste\%20generation\%20and\%20its\%20management $\% 20$ system $\% 20$ th.pdf.

[50]. Haylamicheal DI, Dalvie AM, Yirsaw DB, Zegeye AH: Assessing the management of healthcare waste in Hawassa city, Ethiopia. Waste Manag Res 2011, 29(8):854-862.

[51]. World Health Organization. Healthcare waste management. Geneva: WHO; October 2004.Fact sheet No 281.

[52]. A.Z. Alagoz, and G. Kocasoy, Treatment and disposal alternatives for health-care waste in developing countries-A case study in Istanbul, Turkey," Waste Management amp; Research, vol. 25, pp. 83-89, 2007.

[53]. Hagen DL, Al-Humaidi F, Marthin A (2001). Infectious waste surveys in a Saudi Arabian hospital. An important quality improvement tool. Am.J. Infect. Control, 29: 198-202.

[54]. Ndidi N, Ochekpe N, Odumosu P, John SA (2009). Waste management in healthcare establishments within Jos Metropolis, Nigeria. Afri. J. Environ. Sci. Technol., 3(12): 459-465. 